06

\title{
Влияние кобальта на адгезионную прочность поликристаллических алмазных покрытий на твердых сплавах WC-Co
}

\author{
(C) С.А. Линник, А.В. Гайдайчук, В.В. Охотников \\ Национальный исследовательский Томский политехнический университет, \\ 634034 Томск, Россия \\ e -mail: linniksa@tpu.ru
}

(Поступило в Редакцию 24 мая 2017 г.)

С использованием методов растровой электронной микроскопии, рамановской спектроскопии и рентгеновского микроанализа проведены исследования влияния кобальта на фазовый состав и адгезионную прочность осаждаемых в плазме аномального тлеющего разряда поликристаллических алмазных покрытий на подложках из твердого сплава WC-Co. Установлено, что каталитическая аморфизация углерода происходит только в процессе непосредственного синтеза алмазного покрытия за счет высокого давления паров кобальта над подложкой, а деградация уже синтезированного алмаза под действием кобальта практически отсутствует.

DOI: 10.21883/JTF.2018.02.45410.2356

\section{Введение}

В настоящее время покрытия из поликристаллического алмаза, осаждаемые методом газофазного синтеза (CVD), считаются наиболее перспективными для повышения износостойкости и эксплуатационных характеристик режущего инструмента при обработке углепластиков, графита, алюмокремниевых сплавов, древесины и др. $[1,2]$. Это связано с рядом уникальных свойств алмазных покрытий, таких как высокая твердость и износостойкость, исключительная теплопроводность и низкий коэффициент трения. Наибольшей износостойкостью при нанесении подобных покрытий обладает инструмент из твердых сплавов на основе карбида вольфрама и кобальта (WC-Co) [3], но на пути его массового применения стоит проблема недостаточной адгезионной прочности покрытия к подложке [4,5]. Отдельные компании (Cemecon, SP3 Diamond Technologies, Mitsubishi и др.) разработали эффективные методики (хранящиеся в режиме ноу-хау) специальной многоступенчатой подготовки подложек перед осаждением алмаза, решающие в основной степени проблему адгезии. В то же время в большом числе научных публикаций суть подготовки твердого сплава перед нанесением алмаза сводится исключительно к удалению поверхностного слоя кобальта [5-7], являющегося катализатором графитизации алмаза $[8,9]$. Известны работы, где авторы описывают эффект графитизации алмаза под действием кобальта не только в процессе осаждения, но и эффект графитизации уже сформированного алмаза $[9,10]$. Также есть работы, в которых описывается диффузия кобальта по границам алмазных кристаллитов и его негативное влияние на рост даже верхних слоев алмазного покрытия [10]. В то же время механизмы аморфизации алмаза (на различных стадиях) под действием кобальта практически не рассматриваются в литературе, что указывает на необходимость уточнения и обобщения экспериментальных данных для правильного понимания физики происходящих процессов.

В настоящей работе проведены исследования влияния кобальта на фазовый состав и адгезионную прочность осаждаемых в плазме аномального тлеющего разряда поликристаллических алмазных покрытий на подложках из твердого сплава $\mathrm{WC}-\mathrm{Co}$, а также рассматривается экспериментально подтвержденный механизм образования слоев аморфного углерода под действием кобальта.

\section{Техника эксперимента}

Образцы твердого сплава, используемого в качестве подложек для алмазных покрытий, представляли собой полированные диски $\varnothing 20 \times 5 \mathrm{~mm}$ из мелкозернистого сплава Н10F $(10 \%$ Сo, размер зерна $\sim 0.9 \mu \mathrm{m})$ производства Sandvik Coromant. Для развития поверхности и удаления оксидного слоя образцы подвергались абразивноструйной обработке частицами $\mathrm{SiC}$, а затем проводилась их декобальтация в растворе $\mathrm{HNO}_{3}: \mathrm{H}_{2} \mathrm{O}$. Для внесения центров зародышеобразования алмаза образцы обрабатывались в ультразвуковой ванне в водной наноалмазной суспензии, после чего очищались в ацетоне.

Осаждение алмазных покрытий проводилось в среде водорода $(99.9999 \%)$ и метана $(99.99 \%)$ в плазменном CVD реакторе на основе аномального тлеющего разряда переменного тока. Детально устройство реактора рассматривалось в работах $[11,12]$. Давление в процессе осаждения контролировалось прецизионным мембранноемкостным датчиком Pfeiffer vacuum CMR 372, потоки газов - регуляторами массового расхода Bronkhorst EL-FLOW, температура образцов фиксировалась при помощи инфракрасного тепловизора ULIRvision TI170.

Температурный отжиг образцов проводился в вакуумной печи при остаточном давлении $5 \cdot 10^{-6}$ Torr, что исключало их окисление и какое-либо загрязнение. Оценка 
Таблица 1. Параметры подготовки и обработки образцов твердого сплава Н10F

\begin{tabular}{|c|c|c|c|c|c|c|c|}
\hline \multirow{3}{*}{$\begin{array}{c}\text { Подготовка } \\
\text { образцов }\end{array}$} & $\begin{array}{l}\text { Абразивная } \\
\text { обработка }\end{array}$ & \multicolumn{3}{|c|}{ Декобальтация } & \multicolumn{3}{|c|}{ Засев алмазными зародышами } \\
\hline & \multirow[b]{2}{*}{$\begin{array}{c}\text { Частицы SiC } \\
\text { (FEPA400) }\end{array}$} & Реактив & Температура & Время & Реактив & Активатор & Время \\
\hline & & $\begin{array}{c}\mathrm{HNO}_{3}: \mathrm{H}_{2} \mathrm{O} \\
-60: 40 \\
\text { (по массе) }\end{array}$ & $70 \pm 1^{\circ} \mathrm{C}$ & $5 \mathrm{~min}$ & $\begin{array}{l}\text { Наноалмазная } \\
(\sim 5 \mathrm{~nm}) \\
\text { суспензия } 0.1 \% \\
\text { (по массе) } \\
\text { в } \mathrm{H}_{2} \mathrm{O}\end{array}$ & $\begin{array}{c}\text { Ультразвук } \\
50 \mathrm{kHz}, \\
50 \mathrm{~W}\end{array}$ & $10 \mathrm{~min}$ \\
\hline \multirow[b]{2}{*}{$\begin{array}{c}\text { Осаждение } \\
\text { алмаза }\end{array}$} & $\begin{array}{c}\text { Способ } \\
\text { активации газа }\end{array}$ & Мощность & Давление & $\begin{array}{c}\text { Состав } \\
\text { атмосферы }\end{array}$ & $\begin{array}{c}\text { Температура } \\
\text { подложки }\end{array}$ & \multicolumn{2}{|c|}{ Скорость осаждения } \\
\hline & $\begin{array}{c}\text { Аномальный } \\
\text { тлеющий } \\
\text { разряд }\end{array}$ & $3 \pm 0.1 \mathrm{~kW}$ & $150 \pm 1$ Torr & $\begin{array}{l}\mathrm{H}_{2} \mathrm{CH}_{4} \\
-100: 5\end{array}$ & $600-1200^{\circ} \mathrm{C}$ & \multicolumn{2}{|c|}{$\begin{array}{c}0.5-5 \mu \mathrm{m} / \mathrm{h} \\
\text { (в зависимости } \\
\text { от температуры } \\
\text { подложки) }\end{array}$} \\
\hline \multirow{2}{*}{ Отжиг } & \multicolumn{2}{|c|}{ Давление } & \multicolumn{2}{|c|}{ Температура } & \multicolumn{3}{|c|}{ Время } \\
\hline & \multicolumn{2}{|c|}{$5 \cdot 10^{-6}$ Torr } & \multicolumn{2}{|c|}{$600-1200^{\circ} \mathrm{C}$} & \multicolumn{3}{|c|}{$120 \mathrm{~min}$} \\
\hline
\end{tabular}

адгезионной прочности проводилась по распространенной $[13,14]$ методике, основанной на анализе характера разрушения пленки при уколе алмазным коническим индентором, применяемом для измерения твердости методом Роквелла. В настоящей работе нагрузка на индентор устанавливалась на уровне $590 \mathrm{~N}$ (60 kgf).

Растровые изображения поверхности образцов были получены на электронном микроскопе Philips SEM 515. Элементный состав поверхности образцов исследовался рентгеновским микроанализатором EDAX ECON IV. Шероховатость поверхности измерялась посредством атомно-силового микроскопа NTEGRA Prima NT-MDT. Исследование фазового состава различных сторон алмазных покрытий проводилось методом рамановской спектроскопии на комплексе Centaur I HR, позволяющем получать спектры комбинационного рассеивания на образцах очень малого размера.

Детально параметры подготовки и обработки образцов твердого сплава приведены в табл. 1 .

\section{Результаты и обсуждение}

Изучение влияния кобальта на фазовый состав и адгезионную прочность осаждаемых алмазных покрытий проводилось в направлении двух механизмов:

1) влияние кобальта непосредственно в процессе конденсации углерода, т. е в процессе образования пленки;

2) последующее влияние кобальта на уже синтезированную алмазную пленку.

Для исследования первого механизма алмазные пленки осаждались при различных температурах $\left(600-1200^{\circ} \mathrm{C}\right)$ на подвергнутые абразивной обработке образцы твердого сплава, а также на образцы, дополнительно подвергнутые операции декобальтации

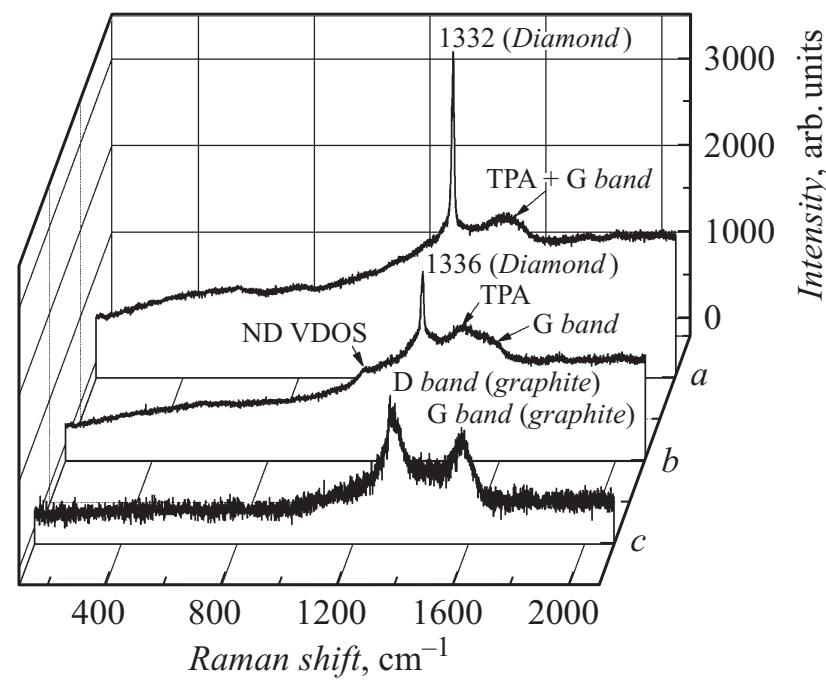

Рис. 1. Рамановские спектры прилегающих к подложке сторон алмазных пленок, осажденных на декобальтированные образцы $\mathrm{WC}-\mathrm{Co}$ при температурах $700(a, b)$ и $1100^{\circ} \mathrm{C}(c)$. Образец $(b)$ после осаждения подвергался отжигу в вакууме при температуре $1200^{\circ} \mathrm{C}$.

поверхности (табл. 1). После осаждения толщин, при которых происходила частичная деламинация покрытий (5-25 $\mathrm{m})$ от подложек при охлаждении, методом рамановской спектроскопии анализировался фазовый состав прилегающей к подложке стороны алмазного покрытия.

На рис. 1, а приведен рамановкий спектр нижней части пленки, осажденной при температуре $700^{\circ} \mathrm{C}$ на образец, подвергнутый декобальтации. Данный спектр содержит интенсивную узкую линию алмаза $1332 \mathrm{~cm}^{-1}$ и следы неалмазного углерода в форме графита (полоса $\mathrm{G}$ - 
$a$

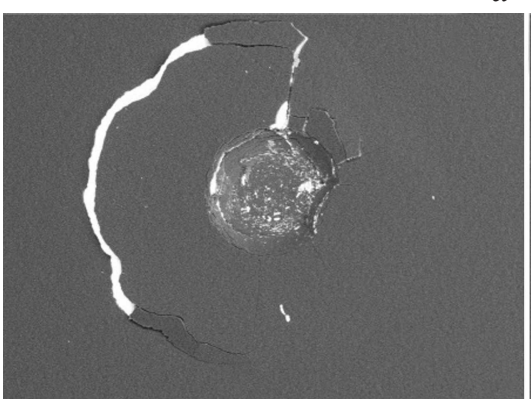

$100 \mu \mathrm{m}$

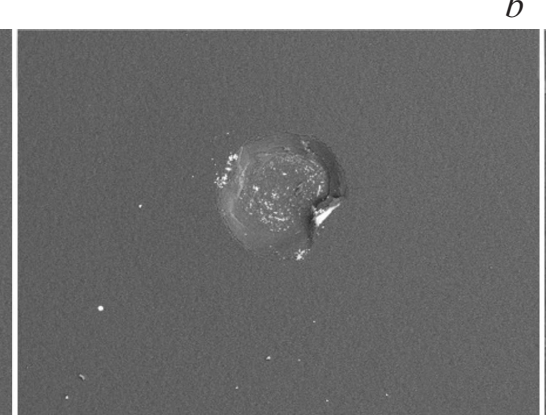

$100 \mu \mathrm{m}$

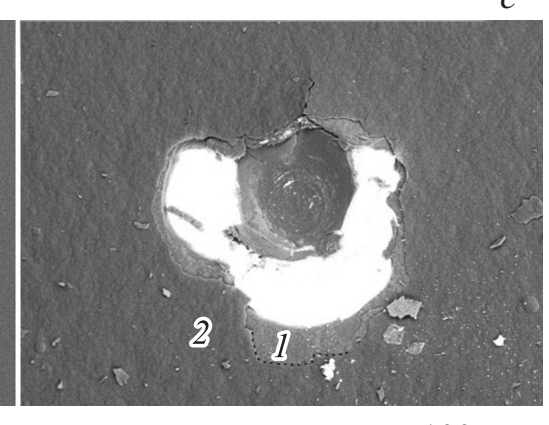

$100 \mu \mathrm{m}$

Рис. 2. РЭМ микрофотографии отпечатков алмазного конического индентора на образцах твердого сплава с алмазными покрытиями, осажденными при температуре $700^{\circ} \mathrm{C}$ без предварительной декобальтации $(a)$ и после декобальтации $(b)$ и при температуре $1100^{\circ} \mathrm{C}$ после декобальтации $(c)$. Область $1(c)$ - слой аморфного углерода, область $2(c)-$ алмазная пленка.

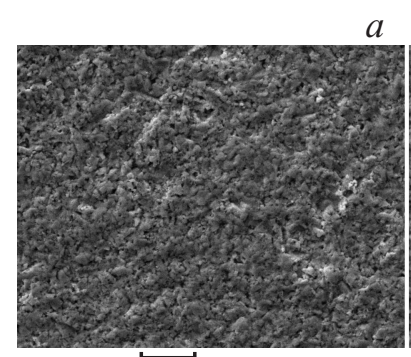

$\times 3500 \stackrel{\overrightarrow{5 \mu \mathrm{m}}}{\rightleftarrows}$

\begin{tabular}{|c|r|c|}
\hline Element & wt.\% & Ra, nm \\
\hline Co & 8.6 & \multirow{2}{*}{74} \\
\cline { 1 - 2 } $\mathrm{W}$ & 50.6 & \multirow{2}{*}{74} \\
\hline $\mathrm{C}$ & 40.8 & \\
\hline
\end{tabular}

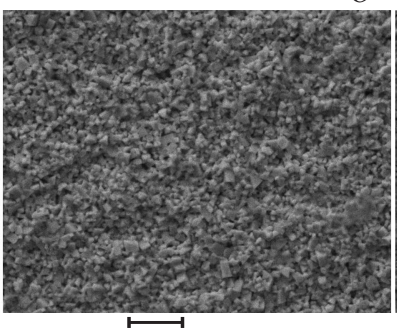

$\times 3500 \stackrel{5 \mu \mathrm{m}}{\mathrm{5}}$

\begin{tabular}{|c|r|r|}
\hline Element & wt.\% & Ra, nm \\
\cline { 1 - 2 } Co & 0 & \multirow{2}{*}{115} \\
\cline { 1 - 2 } $\mathrm{W}$ & 54.5 & \multirow{2}{*}{115} \\
\hline $\mathrm{C}$ & 45.5 & \\
\hline
\end{tabular}

$b$

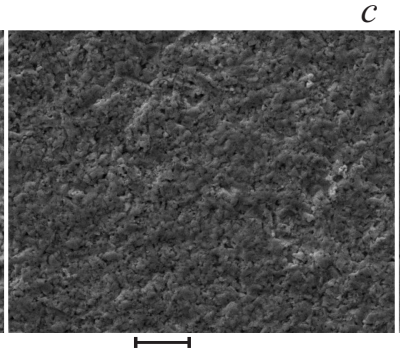

$\times 3500 \stackrel{\overrightarrow{5 \mu \mathrm{m}}}{\longmapsto}$

\begin{tabular}{|c|r|c|}
\hline Element & wt.\% & Ra, nm \\
\hline Co & 3.6 & \multirow{2}{*}{101} \\
\cline { 1 - 2 } W & 52.9 & \multirow{2}{*}{10} \\
\hline C & 43.5 & \\
\hline
\end{tabular}

$c$

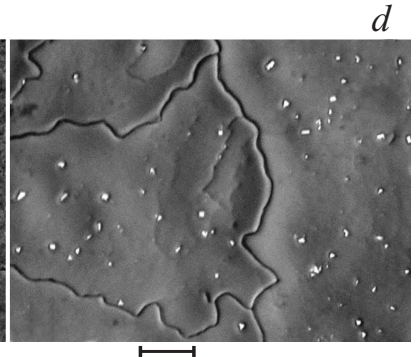

$\times 3500 \stackrel{5 \mu \mathrm{m}}{2}$

Рис. 3. Микрофотографии поверхностей, элементный состав и шероховатость поверхности образцов твердого сплава после абразивной обработки $(a)$, после декобальтации $(b)$, после декобальтации и последующего отжига в вакууме при $1200^{\circ} \mathrm{C}(d)$, и поверхности образца под алмазной пленкой, осажденной при 700 и отожженного при $1200^{\circ} \mathrm{C}(c)$.

$\left.1560 \mathrm{~cm}^{-1}\right)$ и трансполиацетилена (ТРА $\left.-1450 \mathrm{~cm}^{-1}\right)$. Подобный спектр характерен для поликристаллических алмазных пленок с небольшой долей неалмазного углерода [15], что свидетельствует об отсутствии эффекта графитизации. В то же время спектр нижней части пленки (рис. 1,c), осажденной на аналогичный образец, но уже при температуре $1100^{\circ} \mathrm{C}$, представляет собой типичную картину не алмазного углерода (полосы графита D $\left(1355 \mathrm{~cm}^{-1}\right)$ и $\left.\mathrm{G}\left(1560 \mathrm{~cm}^{-1}\right)\right)$ [16]. При этом спектр верхней части данной пленки аналогичен спектру на рис. $1, a$. Все это свидетельствует о блокирующем действии кобальта на образование алмазной фазы на первых стадиях роста пленки. Образование же алмазного слоя поверх неалмазного углерода свидетельствует о том, что прилегающий к подложке неалмазный слой блокирует диффузию кобальта. На рис. 2,c показана микрофотография области пленки на данном образце после укола алмазным индентором (метод Роквелла). Видно, что пленка состоит из двух слоев (области 1 и 2 рис. 2,c). Область 1 - это неалмазный углерод толщиной $0.5-0.9 \mu \mathrm{m}$ с содержанием кобальта от 1 до $4 \mathrm{mass} \%$, а область 2 - алмазная пленка. Алмазный слой имеет крайне слабую адгезию к неалмазному и соответственно к подложке. Табл. 2 отражает экспериментальные зависимости фазового состава прилегающих к подложкам поверхностей алмазных пленок, осаждаемых при различных температурах на образцы твердого сплава с декобальтацией и без нее. Как видно, при температурах более $1000^{\circ} \mathrm{C}$ пленки имеют нижний слой из неалмазного углерода даже при предварительной декобальтации поверхности, а без удаления кобальта этот слой имеет аморфную структуру даже при низких температурах осаждения $\left(710^{\circ} \mathrm{C}\right)$. Причиной роста аморфного (а не алмазного) слоя, безусловно, является негативное действие кобальта. Для образцов с удаленным слоем кобальта на поверхности данный эффект наблюдается только при высоких температурах, что указывает на его выход на поверхность. Поскольку температура плавления кобальта (т.е. появление способности перемещаться между кристаллитами карби- 
да вольфрама) составляет $1495^{\circ} \mathrm{C}$ (что много выше температуры осаждения алмаза), причиной его выхода на поверхность при температуре свыше $1000^{\circ} \mathrm{C}$ может быть только сублимация при субатмосферном давлении (давление насыщенных паров кобальта при $1069^{\circ} \mathrm{C}$ достигает $10^{-3}$ Torr [17]). Наличие паров кобальта над поверхностью образца объясняет блокирование роста алмазной кристаллической фазы (из-за невозможности встраивания кобальта в решетку алмаза). Рост же алмаза поверх аморфного углерода объясняется блокированием выхода паров кобальта слоем этого же самого аморфного углерода.

На рис. 2 приведены РЭМ микрофотографии отпечатков алмазного индентора на образцах твердого сплава с алмазными покрытиями одинаковой толщины $(7 \mu \mathrm{m})$, но с различной подготовкой поверхности и при различной температуре. Как видно, хорошей адгезией обладает лишь покрытие, осажденное при температуре $800^{\circ} \mathrm{C}$ на образце с предварительной декобальтацией (рис. 2,b). Покрытие на образце, не подвергавшемся декобальтации и осажденное также при температуре $800^{\circ} \mathrm{C}$, обладает существенно более слабой адгезией (рис. 2,a). Рамановский спектр нижней части пленки на данном образце полностью аналогичен приведенному на рис. 1, $c$, т.е. представляет собой неалмазный углерод; но толщина аморфного слоя на нем не превышает $0.5 \mu \mathrm{m}$. Адгезия покрытия на образце, подвергшегося декобальтации, но осажденного при температуре $1100^{\circ} \mathrm{C}$, также крайне низка по аналогичной причине (в этом случае толщина аморфного слоя достигала $0.9 \mu \mathrm{m})$. Из полученных данных можно сделать вывод, что без декобальтации давление паров кобальта над поверхностью подложки достаточно высоко даже при самых низких температурах роста алмаза $\left(600-700^{\circ} \mathrm{C}\right)$. В случае же использования декобальтации давление паров кобальта над подложкой достигает аналогичных значений только при высоких температурах (свыше $\left.1000^{\circ} \mathrm{C}\right)$.

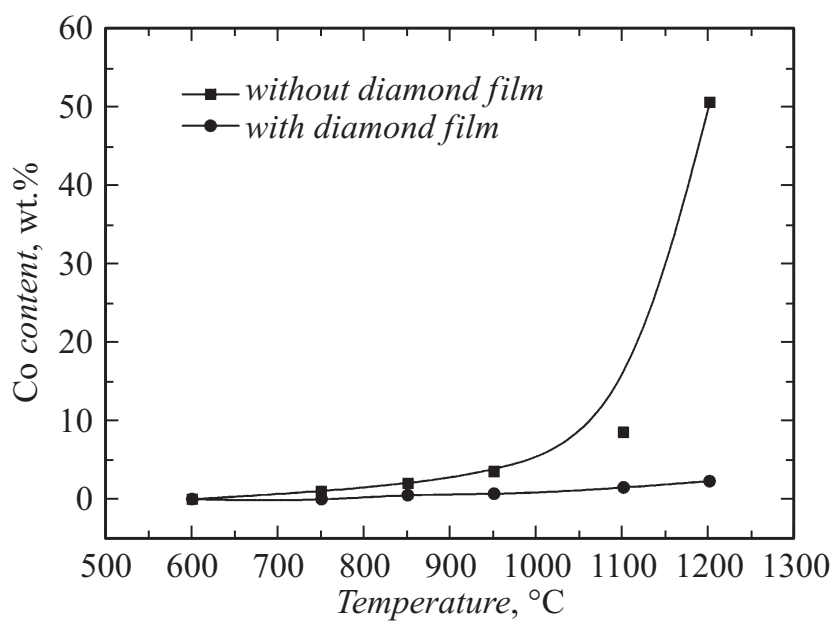

Рис. 4. Зависимости содержания кобальта на поверхности декобальтированного твердого сплава с алмазным покрытием и без него после отжига при различных температурах.
Таблица 2. Экспериментальные зависимости фазового состава прилегающих к подложкам поверхностей алмазных пленок, осаждаемых при различных температурах на образцы твердого сплава с декобальтацией и без нее

\begin{tabular}{c|c|c}
\hline Температура, ${ }^{\circ} \mathrm{C}$ & С декобальтацией & Без декобальтации \\
\hline 710 & $\mathrm{X}$ & $\mathrm{O}$ \\
820 & $\mathrm{X}$ & $\mathrm{O}$ \\
900 & $\mathrm{X}$ & $\mathrm{O}$ \\
960 & $\mathrm{X}$ & $\mathrm{O}$ \\
1050 & $\mathrm{O}$ & $\mathrm{O}$ \\
1110 & $\mathrm{O}$ & $\mathrm{O}$
\end{tabular}

Прим ечани е. $\mathrm{X}-$ алмаз, $\mathrm{O}-$ неалмазный углерод.

Микрофотографии поверхностей, элементный состав и шероховатость поверхности данных образцов до осаждения покрытий приведены на рис. $3, a, b$. Как видно, после декобальтации содержание кобальта на поверхности падает с 8.6\% до 0 нуля. Шероховатость же после декобальтации возрастает (за счет частичного удаления связки между кристаллитами), что также способствует повышению адгезионной прочности покрытий. Для оценки степени выхода кобальта на поверхность декобальтированных образцов с покрытием и без него проводился их отжиг в вакуумной печи при различных температурах. Толщина покрытия на всех образцах была одинакова и равнялась $7 \mu \mathrm{m}$. Результаты приведены на рис. 4. Как видно, степень обогащения поверхности образцов кобальтом под покрытием и без покрытия кардинально отличается. Так, при температуре отжига $1200^{\circ} \mathrm{C}$ содержание кобальта на поверхности под пленкой не превышает 3.6 mass $\%$, в то время при отжиге без покрытия его содержание достигает 50.5\%. Микрофотографии, элементный состав и шероховатость поверхности данных образцов приведены на рис. $3, c, d$.

Анализ рамановских спектров нижних сторон покрытий на отожженных образцах показывает, что существенной аморфизации прилегающего к поверхности подложки алмаза не наблюдается. На рис. $1, b$ приведен спектр нижней стороны пленки с образца, выращенного при $700^{\circ} \mathrm{C}$ и отожженного при температуре $1200^{\circ} \mathrm{C}$. Заметно некоторое снижение интенсивности алмазного пика $\left(1332 \mathrm{~cm}^{-1}\right)$ и увеличение доли трансполиацетилена $\left(1450 \mathrm{~cm}^{-1}\right)$. Также наблюдается появление следов колебательных состояний, характерных для наноалмаза $\left(1140-1190 \mathrm{~cm}^{-1}\right)$ [18]. Такой характер изменения спектра пленок указывает на медленно проходящее ступенчатое видоизменение решетки алмаза под действием кобальта. Адгезия алмазных покрытий на всех отожженных образцах практически не изменилась, а отпечатки алмазного индентора полностью идентичны до отжига (рис. 2,b), что подтверждает незначительность уровня аморфизации прилегающих к подложкам слоев алмазных покрытий при отжиге. 


\section{Выводы}

Проведенные исследования показывают, что содержание кобальта на поверхности твердого сплава существенно влияет на фазовый состав осаждаемых алмазных покрытий и процесс этот сильно зависит от температуры осаждения. Установлено, что каталитическая аморфизация углерода наблюдается в явной мере только в процессе роста углеродного покрытия и причиной этому является высокое содержание кобальта в газовой фазе над подложкой, которое и препятствует нормальному росту алмазных кристаллитов. Исследование действия кобальта на уже синтезированный алмазный слой показало, что кардинальных изменений (полной аморфизации) в фазовом составе алмаза не наблюдается даже при температуре $1200^{\circ} \mathrm{C}$. Показано, что интенсивность выхода кобальта на поверхность твердого сплава с уже осажденным покрытием на порядок ниже, чем без покрытия. Это указывает на то, что осаждение алмазных покрытий на твердосплавные подложки следует проводить сначала при температурах не более $900^{\circ} \mathrm{C}$, а уже после образования сплошной алмазной пленки температура может повышаться без ущерба для адгезии к подложке. Декобальтация подложек перед осаждением необходима, так как прямой контакт с кобальтом не позволяет алмазной пленке расти даже при самых низких температурах осаждения $\left(<700^{\circ} \mathrm{C}\right)$.

Работа выполнена при поддержке гранта президента РФ (МК-5516.2016.8) и грантов РФФИ (№ 16-32-60018 Мол_а_дк и № 16-32-00008 Мол_а).

\section{Список литературы}

[1] Oles E.J., Inspektor A., Bauer C.E. // Diam. Relat. Mater. 1996. Vol. 5. P. 617.

[2] Tyczyǹski P., Lemaǹczyky J., Ostrowski R. // Aircraft Engineer. Aerospace Technol.: An Intern. J. 2014. Vol. 86. N 4. P. 312.

[3] Polini R. // Thin Sol. Film. 2006. Vol. 515. N 4.

[4] Dos Santos S.I., Balzaretti N.M., da Jornada J.A.H. // Diam. Relat. Mater. 2006. Vol. 15. N 9. P. 1457.

[5] Barletta M, Rubino G., Gisario A. // Wear. 2011. Vol. 271. N 9-10. P. 2016.

[6] Wei Q., Ashfold M.N.R., Mankelevich Y.A., Yu Z.M., Liu P.Z., Ma L. // Diam. Relat. Mater. 2011. Vol. 20. P. 641.

[7] Silva Neto J.V., Rodríguez L.A.A., Fraga M.A., Contin A., Campos R.A., Corat E.J. // Trava Airoldi. Rev. Bras. Apl. Vac. 2016. Vol. 35. N 1. P. 53.

[8] Suzuki H., Matsubara H., Horie N. // J. Jpn. Soc. Powder Metall. 1986. Vol. 33. P. 262.

[9] Haubner R., Lindbauer A., Lux B. // Diam. Relat. Mater. 1993. Vol. 2. N 12. P. 1505.

[10] Haubner R., Schubert W.D., Lux B. Proceedings of the $14^{\text {th }}$ Intern. Plansee Seminar. 1997. Vol. 3. P. 16.

[11] Linnik S.A., Gaydaychuk A.V. // Diam. Relat. Mater. 2013. Vol. 32. P. 43.

[12] Linnik S.A., Gaidaichuk A.V. // Tech. Phys. Lett. 2012. Vol. 38. P. 258.
[13] Trava-Airoldi V.J., Corat E.J., Ferreira N.G., N.F. Leite // Braz. J. Phys. 1997. Vol. 27/A. N 4. P. 88.

[14] Drory M.D., Hutchinson J.W. // Mat. Res. Soc. Symp. Proc. 1995. Vol. 383. P. 173.

[15] Yan X., Wei J., Guo J., Hua C., Liu J., Chen L., Hei L., Li C. // Diam. Relat. Mater. 2017. Vol. 73. P. 39.

[16] Ferrari A. // Sol. Stat. Commun. 2007. Vol. 143. P. 47.

[17] Кикоин И.К. Таблицы физических величин. М.: Атомиздат, 1976. $1006 \mathrm{c}$.

[18] Kulisch W., Popov C., Rauscher H., Rinke M., Veres M. // Diam. Relat. Mater. 2011. Vol. 20. P. 1076. 